\title{
EVALUASI KEPUASAN KONSUMEN TERHADAP PELAYANAN KEFARMASIAN DI APOTEK KOTA YOGYAKARTA
}

\author{
EVALUATION OF COSTUMER SATISFACTION WITH \\ PHARMACEUTICAL CARE AT PHARMACY \\ IN YOGYAKARTA
}

\author{
Faridah Baroroh \\ Fakultas Farmasi Universitas Ahmad Dahlan, \\ Jl. Prof. Dr. Soepomo, Janturan, Yogyakarta \\ Email : ida_br@yahoo.com
}

\begin{abstract}
ABSTRAK
Kepuasan konsumen terhadap pelayanan kefarmasian di apotek dapat diukur dengan membandingkan antara harapan konsumen terhadap kualitas pelayanan kefarmasian yang diinginkan dengan kenyataan yang diterimanya. Tujuan penelitian adalah untuk mengetahui gambaran dimensi-dimensi kualitas pelayanan kefarmasian yang diharapkan, dianggap penting, dan yang memiliki kinerja yang baik dengan model kualitas pelayanan kefarmasian terhadap konsumen apotek di Kota Yogyakarta. Penelitian ini dilakukan dengan metode observasional deskriptif dan hasil penelitian disajikan dengan diagram kuadran. Hasil penelitian menunjukkan bahwa konsumen apotek di Kota Yogyakarta puas terhadap pelayanan kefarmasian dalam dimensi Tangible dan Empathy. Hal ini ditunjukkan dengan dimensi Tangible dan Empathy berada di kuadran II pada diagram. Sedangkan pada dimensi Assurance, Responsiveness dan Reliability konsumen kurang puas karena konsumen beranggapan kinerja apotek masih rendah dibandingkan harapan konsumen. Hal ini ditunjukkan dengan dimensi Assurance, Responsiveness dan Reliability berada di kuadran III pada diagram.
\end{abstract}

Kata kunci : kepuasan konsumen, pelayanan kefarmasian, apotek

\begin{abstract}
Customer satisfaction with pharmaceutical care in pharmacy can be measured by comparing the expectations of consumers on the quality of pharmacy services desired by the fact that it received. This study was aimed to identify the dimensions of the expected quality of pharmaceutical care, is considered important, and which has a good performance with a model of quality pharmaceutical care to costumer at pharmacy in Yogyakarta. This study was observational descriptive method and the results are presented with quadrant diagram. The results showed that the costumer at pharmacy in Yogyakarta satisfied with pharmaceutical care in Tangible and Empathy dimension. The Tangible and Empathy dimensions are in quadrant II of the diagram. Howefer, the Assurance, Responsiveness and Reliability dimension, costumers less satisfied because the assume of patients if the pharmacy performance is still lower than the expectations of consumers. That showed the Assurance, Responsiveness and Reliability dimensions are in quadrant III of the diagram.
\end{abstract}

Keywords : costumer satisfaction, pharmaceutical care, pharmacy 


\section{PENDAHULUAN}

Pelayanan kesehatan yang bermutu tinggi dimulai dengan standar etika manajemen yang tinggi pula. Secara ekstrim dikatakan bahwa kualitas merupakan faktor dasar yang mempengaruhi pilihan konsumen untuk berbagai jenis jasa yang berkembang pesat dewasa ini. Pelayanan kefarmasian adalah suatu pelayanan langsung dan bertanggungjawab kepada pasien, berkaitan dengan sediaan farmasi dengan maksud mencapai hasil yang pasti untuk meningkatkan mutu kehidupan pasien (Anonim, 2009).

Pelayanan pada dasarnya dapat dikatakan sebagai suatu tindakan dan perlakuan atau cara melayani orang lain untuk memenuhi apa yang menjadi kebutuhan dan keinginannya. Tingkat kepuasan konsumen atas suatu pelayanan dapat diukur dengan membandingkan antara harapan konsumen terhadap kualitas pelayanan yang diinginkan dengan kenyataan yang diterimanya atau dirasakan (Stefanus, 2008)

Kualitas dapat didefinisikan sebagai totalitas dari suatu keistimewaan dan karakteristik dari suatu produk atau jasa yang menunjang kemampuan produk atau jasa tersebut untuk memuaskan dan memenuhi kebutuhan (Kotler, 2006). Pengukuran kualitas jasa dalam model SERVQUAL didasarkan pada skala multi-item yang dirancang untuk mengukur harapan dan persepsi pelanggan, serta gap diantara keduanya dalam dimensi-dimensi utama kualitas jasa. Dimensi utama kualitas jasa tersebut adalah reliabilitas (reliability), daya tanggap (responsiveness), jaminan (assurance), empati (emphaty), dan bukti fisik (tanggibles) (Fandy Tjiptono, 2000).

Kualitas jasa berpusat pada upaya pemenuhan dan keinginan pelanggan serta ketepatan penyampaiannya untuk mengimbangi harapan pelanggan. Ada dua faktor utama yang mempengaruhi kualitas jasa yaitu expected service dan perceived service (Parasuraman dkk., 1994). Bila jasa yang diterima atau dirasakan (perceived service) sesuai dengan yang diharapkan (expected service), maka kualitas jasa dipersepsikan baik atau memuaskan. Jika jasa yang diterima melampaui harapan pelanggan, maka kualitas jasa dipersepsikan sebagai kualitas yang ideal, demikian pula sebaliknya, dengan demikian, baik tidaknya kualitas jasa tergantung pada kemampuan penyedia jasa dalam memenuhi harapan pelanggannya secara konsisten (Jasfar, 2005).

Harapan pelanggan adalah keyakinan tentang pemberian pelayanan yang berfungsi sebagai standar dalam menilai kinerja. Karena pelanggan membandingkannya dengan persepsi pada saat menilai kualitas pelayanan, mengetahui harapan konsumen menjadi sangat penting bagi pemasar. Kesalahan dalam menilai keinginan pelanggan dapat mengakibatkan kehilangan pelanggan. Pelanggan biasanya mempersepsikan pelayanan berdasarkan kualitas pelayanan dan seberapa besar produk tersebut memuaskan keinginannya dibandingkan dengan pengalamannya secara keseluruhan (Zeithaml dan Bitner, 1996).

Apotek sebagai salah satu bentuk pelayanan kesehatan kepada masyarakat agar tetap dapat bersaing perlu memperhatikan kepuasan pelanggan melalui pelayanan yang diberikan. Berdasarkan hal tersebut, maka perlu dilakukan penelitian tentang Analisis Service Quality serta analisis kepentingan kinerja di apotek (menurut persepsi pelanggan) dan berusaha mengungkapkan elemen pelayanan yang perlu mendapat perhatian sebagai langkah strategis dalam menentukan keputusan manajerial untuk pelayanan kepada konsumen.

Tujuan dari penelitian ini adalah mengetahui gambaran dimensi-dimensi kualitas pelayanan kefarmasian yang diharapkan, dianggap penting, dan yang memiliki kinerja yang baik dengan model kualitas pelayanan kefarmasian terhadap konsumen apotek di Kota Yogyakarta. 


\section{METODE PENELITIAN}

\section{Alat}

Alat yang digunakan untuk penelitian berupa kuesioner, kuesioner digunakan untuk mengetahui gambaran dimensi-dimensi kualitas pelayanan kafarmasian yang diharapkan, dianggap penting, dan yang memiliki kinerja cukup baik menurut model kualitas pelayanan (SERVQUAL) di apotek.

\section{Bahan}

Bahan yang digunakan dalam penelitian adalah data primer berupa jawaban kuesioner dari responden.

\section{Jalannya Penelitian}

\section{Rancangan Penelitian}

Jenis penelitian adalah penelitian non eksperimental dengan rancangan observasional yang bersifat deskriptif dengan pendekatan kuantitatif. Data diperoleh dari kuesioner yang dibagikan kepada responden konsumen apotek di Kota Yogyakarta. Kemudian data yang diperoleh dianalisis dengan analisis kesenjangan (Gap) dan disajikan dalam diagram kartesius.

\section{Pengambilan Sampel}

Pengambilan sampel pasien dilakukan dengan metode purposive sampling atau pengambilan sampel bertujuan. Sampel penelitian adalah pasien atau orang yang mewakili pasien untuk datang ke apotek dengan kriteria inklusi pelanggan/pasien yang sudah pernah datang (lebih dari sekali) ke apotek dan bersedia menjadi responden dan kriteria eksklusi tidak bersedia menjadi responden. Berdasarkan rumus Nawawi (1995) untuk menghitung jumlah sampel minimum diperoleh hasil 96 orang.

\section{Pemilihan Lokasi Penelitian}

Penelitian dilakukan di beberapa apotek di kota Yogyakarta, dengan kriteria apotek yang menjadi tempat pengumpulan data adalah beberapa apotek yang mewakili sebaran lokasi wilayah, utara, selatan, timur dan barat dimana masing-masing kategori apotek diambil 4 apotek sebagai lokasi penelitian.

\section{Analisis Data}

Data yang diperoleh dari kuesioner direkapitulasi dan diberikan scoring yang ditetapkan dengan skala yang menggunakan ketentuan sebagai berikut :

a. Untuk pertanyaan favourable.

1) Jawaban sangat setuju atau sangat penting mendapat skor : 4

2) Jawaban setuju atau penting mendapat skor : 3

3) Jawaban tidak setuju atau tidak penting mendapat skor : 2

4) Jawaban sangat tidak setuju atau sangat tidak penting mendapat skor : 1

b. Untuk pertanyaan unfavourable

1) Jawaban sangat setuju atau sangat penting mendapat skor : 1

2) Jawaban setuju atau penting mendapat skor : 2

3) Jawaban tidak setuju atau tidak penting mendapat skor : 3

4) Jawaban sangat tidak setuju atau sangat tidak penting mendapat skor :4

Dalam hal ini pada kuesioner yang telah disebarkan terdiri dari item pertanyaan favourable dan pertanyaan unfavourable. Analisis yang dilakukan pada penelitian ini menggunakan pendekatan statistik deskriptif. Analisa data yang dilakukan dalam penelitian ini secara teknis adalah sebagai berikut : 
a. Analisis untuk mengetahui kualitas pelayanan yang dapat memuaskan pelanggan dengan cara :

1) Analisis kuantitatif indeks kualiltas pelayanan untuk mengetahui kedudukan kepuasan pelanggan di Apotek. Indeks kepuasan pelanggan dapat dianalisa berdasarkan model Weighted Servqual sebagai berikut :

$$
I k j=\sum_{I=1}^{n} \operatorname{Iij}(P i j-E i j)
$$

Keterangan :

Ikj = indeks total kualitas pelayanan

Iij = bobot kepentingan atribut I dari objek j

Pij = performance I pada objek $\mathrm{j}$

Eij = ekspektasi/harapan atribut I pada objek j

$\mathrm{N} \quad=$ jumlah pertanyaan

Berdasarkan model Weighted Servqual ini kedudukan kepuasan pelanggan dapat diketahui melalui nilai indeks kepuasan pelanggan secara keseluruhan dengan membandingkan indeks total kualitas pelayanan maksimum dan minimum yang dicapai.

2) Analisis statistik deskiptif dilakukan untuk menilai atribut pelayanan menurut nilai maksimum, minimum serta persentase kumulatif tingkat harapan, kinerja dan kepentingan di Apotek.

3) Analisis kuantitatif terhadap kualitas jasa yang berdasarkan pada lima dimensi berkualitas yaitu berwujud (tangibles), keandalan (reliability), daya tanggap (responsiveness), jaminan (assurance), serta empati (empathy) dari pelanggan di Apotek.

4) Analisis kuantitatif untuk mengetahui kesenjangan antara harapan pelanggan akan kualitas pelayanan dengan pelayanan yang dirasakannya di Apotek.

Kesenjangan menggambarkan selisih (gap) antara persepsi pelanggan terhadap pelayanan yang diberikan dengan harapan pelanggan. Angka negatif akan menunjukkan bahwa harapan pelanggan tidak terpenuhi sedangkan angka positif menunjukkan bahwa harapan pelanggan terpenuhi. Rumusnya adalah sebagai berikut :

$$
\begin{aligned}
& \boldsymbol{G}=\boldsymbol{P}-\boldsymbol{E} \\
& \text { Dimana : } \\
& \mathrm{G}=\text { Kesenjangan (gap) } \\
& \mathrm{P}=\text { Persepsi pelanggan terhadap } \\
& \quad \begin{array}{l}
\text { pelayanan (perception of } \\
\text { delivered) }
\end{array} \\
& \mathrm{E}=\text { Expectation of service }
\end{aligned}
$$

b. Analisa kepentingan-kinerja dari pelanggan terhadap pelayanan kefarmasian di Apotek

\section{HASIL DAN PEMBAHASAN}

\section{Customer Satisfaction Index}

Customer Satisfaction Index digunakan untuk menganalisis tingkat kepuasan pasien apotek secara menyeluruh dengan melihat tingkat harapan dari atribut-atribut produk atau jasa.

Tabel I. Customer Satisfaction Index

\begin{tabular}{ccl}
\hline No & Nilai & \multicolumn{1}{c}{ Kategori } \\
\hline 1 & 1 & Sangat Tidak Penting \\
2 & 2 & Tidak Penting \\
3 & 3 & Penting \\
4 & 4 & Sangat Penting \\
\hline
\end{tabular}

Nilai Customer Satisfaction Index di dalam penelitian ini di bagi ke dalam kriteria sesuai penggunaan penilaian Likert poin 4 dari tingkat sangat tidak penting sampai dengan sangat penting. 


\section{Analisis Kesenjangan (Gap)}

Berdasarkan hasil analisis kesenjangan, maka dapat diketahui bahwa kinerja seluruh atribut masih berada di bawah harapan responden. Beberapa atribut yang berada di atas nilai rata-rata selisih bobot merupakan atribut yang perlu di prioritaskan untuk diperbaiki (Tabel II). Atribut yang perlu di prioritaskan dari hasil penelitian ini adalah Assurance dan Responsiveness. Pada atribut Assurance dan Responsiveness nilai kesenjangan antara harapan dan kinerja yang dirasakan konsumen cukup besar di atas nilai rata-rata kesenjangan.

Dari nilai selisih pada Tabel II diketahui bahwa atribut yang perlu di prioritaskan dari hasil penelitian ini adalah Assurance dan Responsiveness. Pelayanan kefarmasian terhadap pasien di apotek di Kota Yogyakarta, perlu perbaikan pada atributatribut yang harus di prioritaskan. Pada atribut Assurance ada selisih yang cukup besar antara harapan atau kepentingan konsumen dan kinerja yang dirasakan konsumen apotek. Rata-rata tingkat kepentingan sebesar 3,20 sedangkan kinerja yang dirasakan konsumen hanya sebesar 2,59, maka ada nilai selisih sebesar 0,61. Beberapa pertanyaan dalam atribut Assurance (Jaminan) diantaranya, konsumen masih merasakan jika apoteker belum dapat memberikan informasi obat secara tepat. Selain itu konsumen masih merasakan kurang percaya dengan obat yang dibeli di apotek tersebut. Kemudian konsumen juga merasakan jika apoteker dalam melayani masih kurang berhati-hati untuk tidak terjadi kesalahan obat dan pengetahuan apoteker perlu di tambah untuk dapat menjawab pertanyaan konsumen terutama pada saat konseling.

Selain Assurance (Jaminan) dalam hal ini Responsiveness (Daya Tanggap) dengan tingkat kepentingan sebesar 3,24 sedangkan kinerja yang dirasakan konsumen hanya sebesar 2,65, maka ada nilai selisih sebesar 0,59 .

Dari pertanyaan dalam atribut Responsive-ness (Daya Tanggap), konsumen masih merasakan jika apoteker di apotek kurang memberikan informasi obat secara jelas dan lengkap.

\section{Diagram Kartesius}

Diagram kartesius menggambarkan indikator-indikator yang mempengaruhi kepuasan konsumen. Perhitungan awal yang dilakukan untuk penempatan, indikatorindikator yang dianggap penting oleh konsumen, serta tingkat kepuasan konsumen adalah pengukuran nilai rata-rata dari rata-rata kemudian dibagi menjadi empat bagian atau kuadran.

Kuadran I. Atribut yang dianggap mempengaruhi kepuasan pelanggan, termasuk unsur- unsur jasa yang dianggap sangat penting namun perusahaan belum melaksanakan sesuai keinginan pelanggan sehingga mengecewakan.

Tabel II. Nilai selisih antara harapan dan persepsi

\begin{tabular}{clccc}
\hline No & Dimensi & Tingkat Kepentingan & Tingkat Kinerja & Selisih \\
\hline 1 & Tangible & 3,50 & 3,07 & 0,43 \\
2 & Reliability & 3,05 & 2,78 & 0,28 \\
3 & Responsiveness & 3,24 & 2,65 & 0,59 \\
4 & Assurance & 3,20 & 2,59 & 0,61 \\
5 & Emphaty & 3,32 & 2,83 & 0,49 \\
& Rata-rata & $\mathbf{3 , 2 6}$ & $\mathbf{2 , 7 8}$ & $\mathbf{0 , 4 8}$ \\
\hline
\end{tabular}


Kuadran II. Unsur jasa yang telah berhasil dilaksanakan perusahaan, sehingga wajib dipertahankan karena dianggap sangat penting dan sangat memuaskan pelanggan.

Kuadran III. Faktor yang kurang penting pengaruhnya bagi pelanggan, pelaksanaannya oleh perusahaan dianggap kurang penting dan kurang memuaskan pelanggan.

Kuadran IV. Faktor yang kurang penting bagi pelanggan tetapi pelaksanaannya berlebihan atau dianggap kurang penting tapi sangat memuaskan pelanggan (Cronin dan Taylor, 1994).

Dari hasil diagram kartesius antara kinerja versus kepentingan pada penelitian ini terlihat

ada tiga atribut atau dimensi di kuadran III termasuk kategori perioritas rendah dan dua atribut atau dimensi di kuadran II yang termasuk kategori di pertahankan. Tiga atribut atau dimensi di kuadran III termasuk kategori perioritas rendah adalah Assurance, Responsiveness dan Reliability. Sedangkan dua atribut atau dimensi di kuadran II yang termasuk kategori di pertahankan adalah Tangible dan Empathy.
Tiga atribut atau dimensi yang ada di kuadran III yaitu Assurance, Responsiveness dan Reliability, dalam hal ini termasuk prioritas rendah, tetapi hal ini perlu diperbaiki untuk meningkatkan capaian harapan konsumen mengenai pelayanan kefarmasian di apotek di kota Yogyakarta. Jadi jika dilihat dari diagram kartesius pada hasil percobaan ada tiga atribut atau dimensi yang ada di kuadran III yaitu Assurance, Responsiveness dan Reliability yang harus diprioritaskan untuk meningkatkan kinerja pelayanan kefarmasian di Apotek di Kota Yogyakarta.

Dari hasil diagram kartesius antara kinerja versus kepentingan pada penelitian ini terlihat ada tiga atribut atau dimensi di kuadran III termasuk kategori perioritas rendah dan dua atribut atau dimensi di kuadran II yang termasuk kategori di pertahankan. Tiga atribut atau dimensi di kuadran III termasuk kategori perioritas rendah adalah Assurance, Responsiveness dan Reliability. Sedangkan dua atribut atau dimensi di kuadran II yang termasuk kategori di pertahankan adalah Tangible dan Empathy.

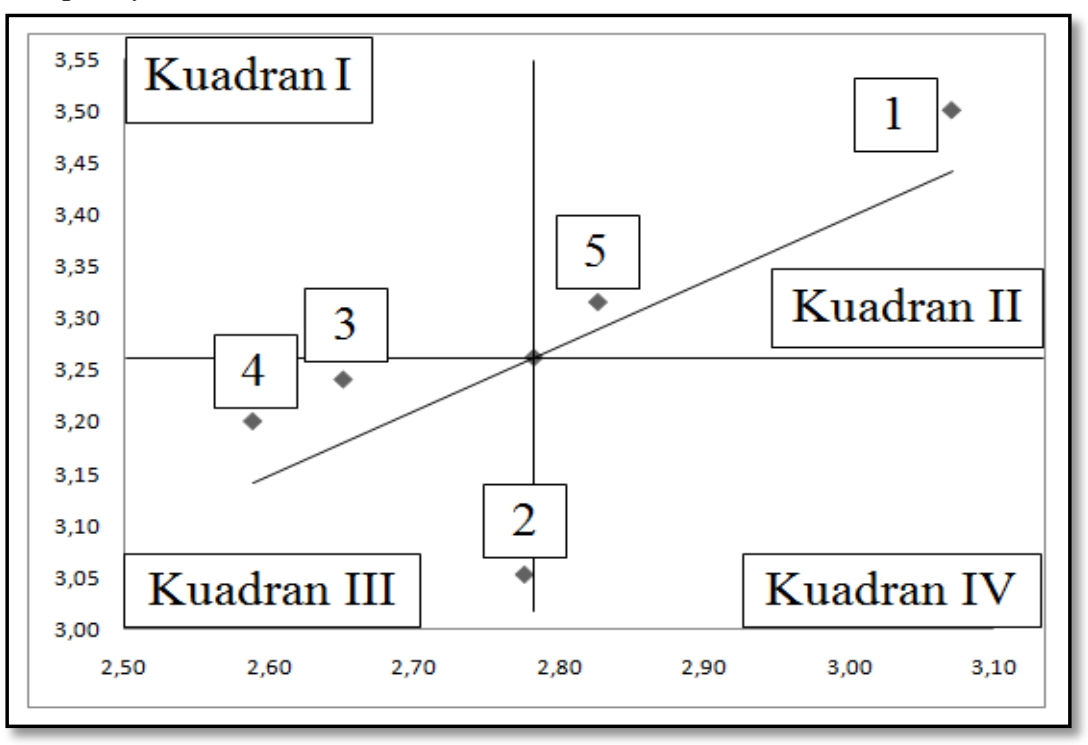

Gambar 1. Diagram kartesius kinerja vs kepentingan 
Tiga atribut atau dimensi yang ada di kuadran III yaitu Assurance, Responsiveness dan Reliability, dalam hal ini termasuk prioritas rendah, tetapi hal ini perlu diperbaiki untuk meningkatkan capaian harapan konsumen mengenai pelayanan kefarmasian di apotek di kota Yogyakarta. Jadi jika dilihat dari diagram kartesius pada hasil percobaan ada tiga atribut atau dimensi yang ada di kuadran III yaitu Assurance, Responsiveness dan Reliability yang harus diprioritaskan untuk meningkatkan kinerja pelayanan kefarmasian di Apotek di Kota Yogyakarta.

\section{KESIMPULAN}

Dari hasil penelitian ini dapat disimpulkan bahwa konsumen apotek di Kota Yogyakarta puas terhadap pelayanan kefarmasian dalam dimensi Tangible dan Empathy. Sedangkan pada dimensi Assurance, Responsiveness dan Reliability pasien kurang puas karena pasien beranggapan kinerja apotek masih rendah dibandingkan harapan konsumen.

\section{DAFTAR PUSTAKA}

Anonim, 2009, Peraturan Pemerintah Republik Indonesia Nomor 51 Tahun 2009 tentang Pekerjaan Kefarmasian diunduh dari http://depkes.go.id/surat_edaran_tanaga _kefarmasian.pdf pada 10 September 2014

Cronin Jr., J.J., dan Taylor, S.A., 1994, SERPERF Versus SERVQUAL : Reconciling Performance based and

\section{Perceptions-Minus-Expectation}

Measurement of Services Quality, Journal of Marketing, Vol. 58, Jan 1994, pp. 125-131.

Fandy., Tjiptono, 2000, Perspektif Manajemen dan Pemasaran Konterporer. Edisi 1, Penerbit Andi, Yogyakarta

Jasfar, F., 2005, Manajemen Jasa Pendekatan Terpadu, Cetakan Pertama, Ghalia Indonesia, Bogor. Hal 47-65.

Kotler, P., 2006, Manajemen Pemasaran, Edisi Kesebelas, Jilid I, Pretince Hall International Inc., New Jersey, 138, 245-246, 344, 372-373, 375-377.

Nawawi, H., 1995, Metode Penelitian Bidang Sosial, Gadjah Mada University Press, Yogyakarta, 159.

Parasuraman, A., Zeithaml, A.V., Berry, L.L., 1994, Reassesment of Expectation as a Comparison Standart in Measuring Service Quality; Implications for Further Research, Journal Marketing, Vol 58, Jan 1994, pp 111-124.

Stefanus, T.K., 2008, Analisa Kesenjangan Kualitas Pelayanan dan Kepuasan Konsumen Pengunjung Plaza Tunjungan Surabaya, Jurnal Manajemen dan Kewirausahaan, Vol.10, No.1, Maret 2008, hal 66-83

Zeithaml, A.V., Bitner, M.J., 1996, Services Marketing, 2 ed., Mc. Graw Hill, North California. 